\title{
Development and Application of Construction technology of Offshore Booster Station
}

\author{
ShengqiangZhangr ${ }^{1, ~ a, ~ X u a n y i Z h a n g ~}{ }^{2, b}$ ChaoFang ${ }^{3, c}$ Huichi Zhang ${ }^{4, d}$ \\ ${ }^{1}$ No.199HaiBinFifteen Road Tianjin Port Bonded Area, China \\ ${ }^{2}$ No.3 Xingang Road, Tanggu, Tianjin, China \\ ${ }^{3}$ No.3 Xingang Road, Tanggu, Tianjin, China \\ ${ }^{4}$ No.688Bohai Oil Road, Tanggu, Tianjin, China P.O.Box.595 \\ asqzhang@cooec.com.cn, bzyx25800616@163.com, cfangchao8172102@163.com, \\ dzhanghui@cooec.com.cn
}

Keywords: offshore booster station, model, construction, installation, construction technology. Abstract. This paper is based on the construction, installation and commissioning of the first offshore booster station - a $220 \mathrm{KV}$ booster station in the Asia Pacific region, and mainly expounds the technology of integrity analysis of offshore booster station model and integrated construction. This paper explains control effect of key construction technology on the construction, installation and other processes; ultimately realize the goal of providing value-added services to customers

\section{Introduction}

China's wind power industry has developed rapidly in recent years, and has become the mainstream of new energy formats. In 2016, the total installed capacity of China was $167.8 \mathrm{GW}$, accounting for $1 / 3$ of the world's total, and becomes the main force in the world wind power development

Since 13th Five-Year, offshore wind power generation has present an exponential growth trend. It is expected by 2020, China's offshore wind power installed capacity will reach 5 million kilowatts. As a "central control center" of offshore wind farms, offshore booster station will collect the current delivered by wind generators in the wind farm, raise the voltage to the design level, and transmit to onshore centralized center for grid connect. It achieves stable offshore wind power grid access, and plays an important role in power transmission of the entire wind farm.

\section{Booster Station Model Integrity and Crash Analysis Technology}

\section{Technical Points of Module Integrity and Crash Analysis Technology}

Carrying capacity limit method $(\gamma \mathrm{S} \leq \mathrm{R})$ to operation conditions of marine structures in load-out, transportation and lifting condition, perform overall structure modeling(Fig. 1), calculation and analysis to the module structure and facilities.

Perform dynamic monitoring, inspection and revision to module design process, results integrity and reliability during construction.

Ensure safe and reliable of the status, construction and operation of the booster station system during whole life cycle.

\section{Application Effect of Module Integrity and Collision Analysis Technology}

Through the booster station overall modeling and analysis, mainly export main member node normal stress, shear stress, and facilities layout, timely detect and correct the node stress problem of structure member at any point.

Ensure that land lifting, offshore transportation and offshore lifting to be safe, effective and successful at one time in the limit. 


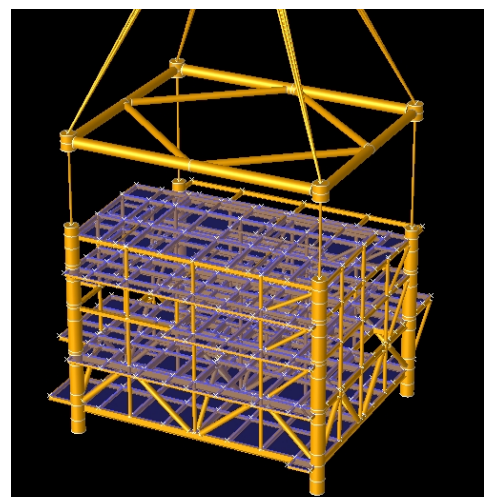

Fig. 1 Structure model

\section{Offshore Booster Station Integrated Construction}

\section{Technical Points of Offshore Booster Station Integrated Construction}

Establish coordination between detail design, shop design, equipment and materials procurement, fabrication, anti-corrosion, outfitting and etc.. Realize the integration of layered modules.

Implement a high degree of coordination and integration of design results, procurement trends, and manufacturer plans.

Make integrated prefabricated list of each deck, track equipment and materials delivery status, and installation of deck column, reinforcement, plaster, equipment, pipeline and piece parts (Fig. 2).Finally achieve integrated construction (Fig. 3)

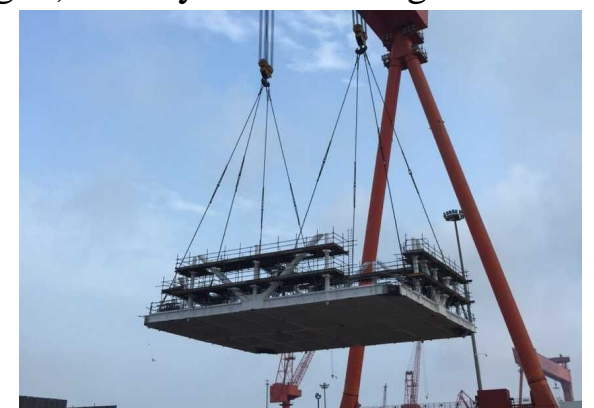

Fig. 2 Lifting of integrated deck

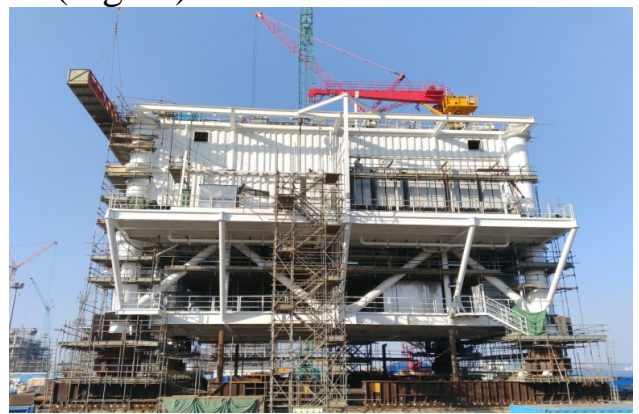

Fig. 3 Integrated construction

\section{Application Effect of Integrated Construction Technology}

Apply integrated construction technology to whole decks of the module. Reduce the crane, Labor and other costs.

Ensure that overall land construction cycle target of booster station is achieved.

\section{Cloud Intelligence Data Acquisition and Analysis Technology}

\section{Technical Points of Cloud Intelligence Data Acquisition and Analysis}

As the core equipment, cloud data acquisition system has high precision distributed data acquisition. The acquisition system adopts 24 bit $\mathrm{AD}$ and $25 \mathrm{MHz}$ speed integration design and applies to data collection of vibration equipment and structure vibration and modal testing of rotating machinery.

Cloud intelligence data will perform the angular displacement, vibration and acceleration detection during overall shipment, offshore transport and offshore lifting of offshore booster station. Make sure the electrical, instrument and control systems meet the requirements of anti-interference during the construction phase before the offshore booster station put into operation. 


\section{Application Effect of Cloud Intelligence Data Acquisition and Analysis Technology}

The monitoring contents include: Dynamic monitoring of impact acceleration and inclination angle of 4 legs during overall shipment, offshore transport and offshore installation of offshore booster station (Fig. 4).

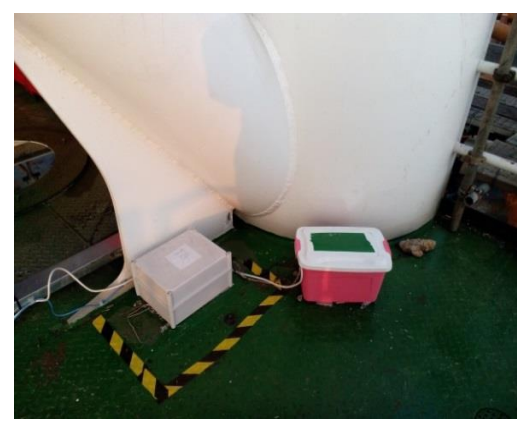

Fig. 4 Layout of the monitoring point

Evaluation contents include: vibration acceleration of 4 legs meet design and equipment requirements during overall shipment, offshore transport and offshore installation of offshore booster station.

Effective monitoring results include: vibration acceleration meet Limit requirement standard during overall shipment, offshore transport and offshore installation of offshore booster station. The maximum acceleration which is $0.135 \mathrm{~g}$ occurs when the vertical impact during shipment of the booster station, less than the limit $0.2 \mathrm{~g}$. The inclination angle is less than the required limit. The maximum inclination angle which is $0.776^{\circ}$ (pitch angle) occurs during shipment of the booster station, less than the limit $10^{\circ}$.

\section{Innovative Application of Ship Stern to Stern Berthing:}

Lifting capacity of booster station is more than 2000t. The lifting capacity of Domestic lifting vessels can meet the lifting requirements of the offshore booster station. Full slewing crane have deep draft.only one vessel can meet the minimum ship draft when lifting. When the vessel is selected, we encountered new problems. And ship stern to stern berthing technology Fig. 5) brings to solve this problem.

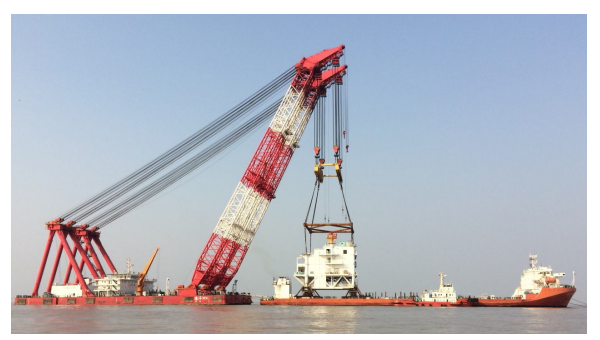

Fig. 5 Lifting by ship stern to stern berthing

This is the first Hoisting operation in shallow water area by using ship stern to stern berthing technology in CNOOC

Theoretical basis: Based on the ship 3D surface model and CGAL geometry algorithm, the ship 3D basic database is established, which can solve the hydro-static parameters in any floating state, and lay the foundation for the solution of the floating state and stability.

Pin-point accuracy for location: Adopt precision GPS equipment.

Use at least one full turn tug to control the direction of the stern of the barge when it is moved rearward

Need to know the site routing and surrounding facilities, and prepare emergency evacuation routes in advance. 
The orientation and the axis of the barge and the crane ship should be in accordance with the main stream. And the cross flow operation shall not be carried out.

All anchors need to be tested for anchor grip and meet the requirements to prevent slipping.

\section{Innovation Effect of Ship Stern to Berthing}

The innovative design solves the problem that the non-rotating crane lifts the heavy structure in the condition of shallow water and small ship draft.

The successful application of the Ship stern to stern berthing plan, opens up a solution for the subsequent use of the non-rotating crane it will save construction costs and reduce the security risk.

The successful application of this innovative technology has greatly guaranteed the construction safety and construction efficiency of the project.

\section{Patented Technology of Single Pile Multi cable Transit Sleeve Installation}

\section{Technical Points of Single Pile Multi cable Transit Sleeve Installation}

The device is divided according to the structure composition (Fig. 6): sleeve ring, riser connected to sleeve ring, support structure. The connection between sleeve ring and multi cable transit is completed onshore as a whole.

Interval distance of sleeve ring is $3 \mathrm{~m}$ to $5 \mathrm{~m}$; The diameter of the sleeve ring grows larger from bottom up

One end of sleeve ring is bell mouthpiece shaped

Support structure adopts square hollow section steel

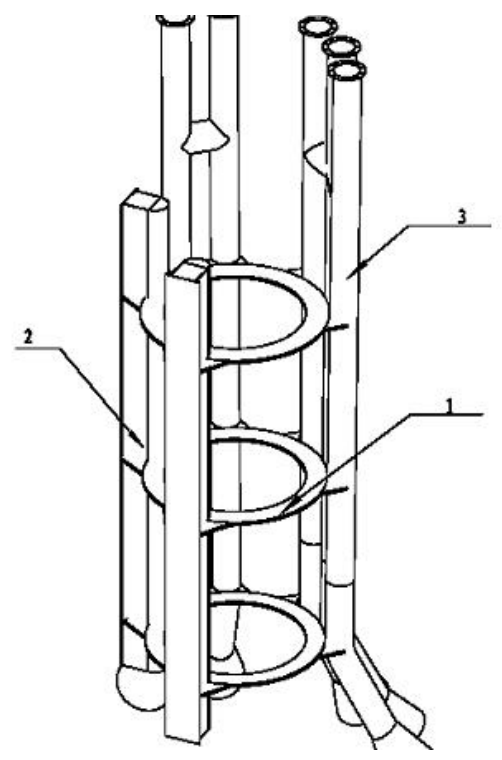

Fig. 6 structure composition(1-sleeve ring2-support structure 3-cable tube)

\section{Application effect of single pile multi cable transit sleeve Installation}

By using this patented technology, we realize quick installation of multiple cable transit sleeves, reduce cost of offshore construction and improve construction efficiency and installation accuracy.

The application of the device reduce cost of offshore construction

\section{Conclusions}

\section{To sum up, the following conclusions are drawn:}

In the early stage of construction, regarding to detailed design results for the booster station provided by the owner, it is necessary to carry out model integrity and collision analysis to prevent major risk of construction safety during onshore hoisting, offshore transportation and offshore integral hoisting. 
Apply integrated construction technology to improve construction efficiency and raise higher requirements for the connection of design, procurement, fabrication and integration

INV3062c cloud intelligence data acquisition and analysis technology is contributive to realize the integrity monitoring of all electrical modules of the booster station under the interference of transportation and hoisting conditions. It is accurate, economical and efficient.

The innovation and application of ship stern to stern berthing plan realizes disposable hoisting of heavy structure in shallow water area and provides a reference example for offshore booster station installation.

The innovation and application of single pile multi cable transit sleeve realizes a stride over from offshore single transit installation to multi transit integration onshore, and greatly reduce the cost of offshore installation and the construction risk.

\section{References}

1. X Yang, S Liu, X Xue.Research and application of open-hole gravel pack sand control technique optimization in horizontal well, Oil Drilling \& Production Technology.

2. QW Mei, XX Chen, LN Wang. Application and analysis of open-hole gravel pack sand control in horizontal well in Wenchang Oilfield. Special Oil \& Gas Reservoirs.

3. M Ma.Horizontal Segmented Gravel Pack Technology and Field Application. China Petroleum Machinery. 